\title{
W syndrome
}

INSERM

\section{Source}

INSERM. (1999). Orphanet: an online rare disease and orphan drug data base. $\underline{W}$ syndrome. ORPHA:2804

W syndrome is characterised by intellectual deficit, epileptic seizures and facial dysmorphism. Skeletal anomalies are also often present. To date, it has been described in six male patients. The mode of transmission appears to be X-linked dominant. 